\title{
Blood pressure, heart diseases and lifestyles of elderly
}

\author{
Pressão arterial, doenças cardiovasculares e hábitos de vida de idosos
}

\author{
Presión arterial, enfermedades cardiovasculares y hábitos de vida de ancianos
}

Paula Cristina Araújo Morais ${ }^{1}$, Rafaella Pessoa Moreira ${ }^{1}$, Paula Alves de Lima ${ }^{1}$, Maria das Graças Fernandes Silva ${ }^{1}$, Jerry Deyvid Freires Ferreira ${ }^{1}$, Emília Soares Chaves Rouberte ${ }^{1}$

Objectives: to investigate the blood pressure values; to identify the history of cardiovascular diseases and lifestyles of elderly at a social assistance reference center. Methods: cross-sectional study, conducted with fifty elderly. A form with questions regarding social data, history of diseases and lifestyles was applied. In sequence, the blood pressure was checked. Results: it was observed that $73.3 \%$ of the elderly had pressure alterations. Systolic alterations were identified in 73.3\%, and diastolic, in $10 \%$ of the elderly. The most frequently referred cardiovascular diseases were hypertension (70.0\%), diabetes mellitus (38.0\%) and dyslipidemia (32.0\%). The most common risk factors were current or past use of tobacco whether active $(68.0 \%)$ or passive $(26.0 \%)$, and physical inactivity (48.0\%). Conclusion: people with altered blood pressure and associated risk factors were identified. This situation may contribute to directing nursing care and addressing the real needs of elderly population.

Descriptors: Arterial Pressure; Aged; Cardiovascular Diseases; Habits; Nursing.

Objetivos: investigar valores da pressão arterial; identificar história de doenças cardiovasculares e hábitos de vida em idosos de um centro de referência da assistência social. Métodos: estudo transversal, realizado com cinquenta idosos. Foi aplicado formulário contendo questões referentes a dados sociais, histórico de doenças e hábitos de vida. Em seguida, verificou-se a pressão arterial. Resultados: averiguou-se que 73,3\% dos idosos apresentaram alterações pressóricas. As alterações sistólicas foram identificadas em $73,3 \%$ e as diastólicas em $10 \%$. As doenças cardiovasculares mais referidas foram hipertensão arterial $(70,0 \%)$, diabetes mellitus $(38,0 \%)$ e dislipidemias $(32,0 \%)$. Os fatores de risco mais presentes foram o uso atual ou passado do tabaco, de forma ativa $(68,0 \%)$, passiva $(26 \%)$ e a inatividade física $(48,0 \%)$. Conclusão: identificaram-se pessoas com alteração da pressão arterial e seus fatores de risco. Tal situação poderá contribuir para o direcionamento do cuidado de enfermagem e atendimento das reais necessidades dessa população.

Descritores: Pressão Arterial; Idoso; Doenças Cardiovasculares; Hábitos; Enfermagem.

Objetivos: investigar valores de la presión arterial; identificar antecedentes de enfermedades cardiovasculares y de hábitos de vida en ancianos de un centro de referencia de la asistencia social. Métodos: estudio transversal, realizado con cincuenta ancianos. Formulario se aplicó con cuestiones relativas a los datos sociales, histórico de enfermedades y hábitos de vida. A continuación, se verificó la presión arterial. Resultados: se constató que 73,3\% de los ancianos tenían alteraciones de presión. Se identificaron cambios sistólicos en $73,3 \%$, y diastólicos en $10 \%$. Las enfermedades cardiovasculares más frecuentes fueron hipertensión $(70,0 \%)$, diabetes mellitus $(38,0 \%)$ y dislipidemias $(32,0 \%)$. Los más presentes factores de riesgo fueron el uso actual o pasado de tabaco, de forma activa $(68,0 \%)$, pasiva $(26,0 \%)$ y inactividad física $(48,0 \%)$. Conclusión: se identificaron personas con presión arterial alterada y sus factores de riesgo. Esta situación podrá contribuir para la atención de enfermería y de las necesidades reales de esta población.

Descriptores: Presión Arterial; Anciano; Enfermedades Cardiovasculares; Hábitos; Enfermería.

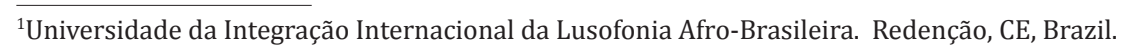

Corresponding author: Paula Cristina Araújo Morais

Unidade Acadêmica dos Palmares. Rodovia CE 060 - KM 51, CEP: 62785-000. Acarape, CE, Brazil. E-mail: paulacristinaenf@yahoo.com.br 


\section{Introduction}

Over the years and advancing technologies, population aging is no longer considered a phenomenon but a social reality, both in developed and developing countries. Several studies report that this fact is directly linked to changes in some health indicators especially those related to fertility ${ }^{(1)}$ and mortality decline and increase in the life expectancy of the population ${ }^{(1-3)}$.

Longevity is a great achievement. However, it comes with challenges, such as maintaining an active life cycle in an age group that stands out for presenting progressive limitations. Recent research shows that the elderly population is affected mainly by noncommunicable chronic diseases ${ }^{(4)}$ that may incur a number of functional impairments and demanding real changes in the lifestyle of these people. Among the most common chronic non-communicable diseases present in the old age is the systemic arterial hypertension, which is a multifactorial clinical condition characterized by high and sustained levels of blood pressure ${ }^{(5)}$.

Arterial hypertension is a public health problem in Brazil and worldwide. It exhibits low control rates and high prevalence, especially among elderly population. The literature describes that about $20.0 \%$ of the adult population is affected by this disease. About $5.0 \%$ are people aged between 18 and 24 years and $58.0 \%$, over 65 years $^{(6)}$, making this last group the largest public.

Arterial hypertension is a significant risk factor for developing complications of cardiovascular nature such as acute myocardial infarction and strokes ${ }^{(7)}$ which are considered important causes of mortality in the territory. Also noteworthy are sudden death, renal failure and acute pulmonary edema ${ }^{(4)}$ which significantly compromise the quality of life of seniors.

The asymptomatic nature of hypertension corroborates for maintenance of inappropriate lifestyle habits. Often, the elderly seek medical care only when some discomfort that may compromise the realization of their daily activities is identified.

Nurses play key roles toward hypertensive patients, roles such as early detection, survey of cardiovascular risk factors and offering of guidelines for taking effective measures to improve the quality of life of elderly. The development of these actions is necessary. Besides detecting pressure changes, it allows for a statistical survey of the main risk factors for development of fatal and non-fatal cardiovascular complications that help to direct nursing care and health professionals while seeking to meet the real needs of the elderly population.

Given the importance attributed to these actions to be performed by nurses, this study aimed to investigate the blood pressure values, identify the history of cardiovascular disease and the lifestyle of elderly patients at a social assistance reference center.

\section{Method}

Descriptive transversal study in which the variables related to blood pressure values and modifiable risk factors for the development of arterial hypertension were investigated. Data were collected from January to June 2013 with a population of fifty elderly participants of the activities developed every week in a social assistance reference center in the municipality of Redemption, CE, Brazil.

$A$ visit to the social assistance reference center of Redemption-Ceará was made with the purpose of knowing the active group of elderly there and to explain the objectives of the study. After clarification of doubts, specific dates were scheduled to perform the data collection with small groups of about five elderly at a time.

In the scheduled dates, the elderly were brought individually to a private room in order to apply the instrument for collection of data with 
questions regarding the history of diseases such as: diabetes mellitus, hypertension, cardiopathies; altered cholesterol and triglycerides levels; risk factors for the development of hypertension such as: active and passive smoking, alcohol consumption, illicit drug use and physical inactivity.

Regarding the presence of cardiovascular diseases, the response of elderly patients was considered. Categories were stablished for smoking habits, namely, nonsmokers, active smokers, passive smokers, former smokers. The use of alcohol and physical activity were categorized into "yes", "no" and "not now". After application of the instrument for collection of data, blood pressure levels were measured. The following equipment was used: sphygmomanometers with aneroid manometers, tested and calibrated, double stethoscopes and cuff sets of varied widths.

Blood pressure assessment was performed in a silent environment with the elderly accommodated in a sitting position, with uncrossed legs, feet flat on the floor, leaning back in a chair and right arm on a table at heart height, free of clothes, with the palm of the hand facing upward and the elbow slightly flexed ${ }^{(5)}$. Before the investigation, we made sure that the elderly was not with full bladder, had not practiced physical exercise, ingested alcoholic drinks, coffee, food and smoked up to 30 minutes prior to the procedure.

The participant had his arm circumference measured for selection of the appropriate cuff, corresponding to $40 \%$. The cuff was positioned approximately 2 to $3 \mathrm{~cm}$ above the cubital fossa and adjusted over the brachial artery. Subsequently, the level of blood pressure was estimated by palpating the radial pulse. The brachial artery was identified by palpation and the bell properly positioned thereon.

The determination of the systolic pressure consisted in the appearance of the first sound (Korotkoff phase I) which raises with increasing speed of deflation; and the determination of the diastolic pressure consisted in the disappearance of sound (Korotkoff phase V). We auscultated about 20
mmHg to $30 \mathrm{mmHg}$ below the last sound in order to confirm its disappearance and then the rapid and complete deflation was performed, thus finishing the procedure $^{(5)}$. Blood pressure measurements were obtained from three consecutive times at intervals of one minute between each scan and the final value considered was the average of the last two measures.

The interpretation of the obtained pressure values was made by comparing them to tables proposed and recognized as suitable for casual measure in the medical office, $(>18 \text { years })^{(5)}$ as follows: Classification Systolic blood pressure mmHg X Diastolic Blood pressure mmHg: Excellent: $<120<80$; Normal: <130<85; Limitrophe: 130 - 139 and 85 - 89; Stage 1 hypertension: 140-159 and 9099; Stage 2 hypertension: $160-179$ and 100-109; Stage 3 hypertension: $>180>110$; and Isolated systolic hypertension: $>140<90$.

After the procedure, the elderly received a card-report with the results of the assessment. If alterations in blood pressure were observed at the first assessment, they were invited to return two days to make new measurements of blood pressure, following the same procedure and criteria used at the first time.

Data were organized in a spreadsheet program Microsoft Excel 2010 and statistical analysis was performed using the program Epi Info version 3.5.2.

Elderly with blood pressure levels considered 'altered' after all the monitoring period were directed for medical evaluation. Those elderly who were already treating the disease and still had alterations recorded were told to seek the specialist following their case, and those who have not searched for specialized accompaniment yet were advised to seek medical service of the health center of their residing area or a particular service, if they so desired.

The research project was approved by the Ethics Research Committee of the Department of Clinical Medicine of the Federal University of Ceará under opinion No. 96,760. 


\section{Results}

The study was conducted with fifty elderly who developed activities in the social assistance reference center of the city of Redemption-Ceará, Brazil.

The majority of the population, $82.0 \%$, consisted of female participants, had average age of 70.95 years, $52.0 \%$ reported not having marital bond, being single, widowed or divorced. Number of years of school education was in average 4.50 years. Regarding the analysis of financial profile, the family income of elderly averaged one thousand three hundred and fifty seven Brazilian reais and sixty-nine cents, and individual income averaged seven hundred and eightyeight Brazilian reais and sixty one cents. Notably, one elder did not know his monthly individual income, and four were unable to respond on family income.

Table 1 shows the distribution of the fifty elderly participants in the study according to the risk of developing cardiovascular diseases.

Table 1 - Distribution of elderly according to risk of developing cardiovascular diseases.

\begin{tabular}{lcc}
\hline Risk factors for cardiovascular diseases & $\mathbf{n ~ ( \% )}$ & IC 95\% \\
\hline Arterial hypertension & $35(70.0)$ & $55.4-82.1$ \\
Yes & & \\
Diabetes Mellitus & $19(38.0)$ & $24.7-52.8$ \\
Yes & $3(6.0)$ & $1.3-16.5$ \\
Does not know & & \\
Cardiopathy & $6(12.0)$ & $4.5-24.3$ \\
Yes & $3(6.0)$ & $1.3-16.5$ \\
Does not know & $16(32.0)$ & $19.5-46.7$ \\
Altered cholesterol and triglycerides levels & $8(16.0)$ & $7.2-29.1$ \\
Yes & & \\
Does not know & $7(14.0)$ & $5.8 \%-26.7$ \\
\hline Stroke &
\end{tabular}

According to the distribution of elderly people with cardiovascular risks, it was noted that more than $30 \%$ of the population presented diseases such as hypertension, diabetes mellitus, altered cholesterol and triglyceride levels.

Table 2 contains the distribution of the elderly by their living habits, which are characterized as cardiovascular risk factors.

Table 2 - Distribution of elderly according to lifestyle

\begin{tabular}{lcc}
\hline Risk factors for cardiovascular diseases & $\mathbf{n}(\mathbf{\%})$ & IC $\mathbf{9 5 \%}$ \\
\hline Active smoking & $11(22.0)$ & $11.5-36.0$ \\
Yes & $23(46.0)$ & $31.8-60.7$ \\
Not currently & & \\
Passive smoking & $8(16.0)$ & $7.2-29.1$ \\
Yes & $5(10.0)$ & $3.3-21.8$ \\
Not currently & & \\
Illicit drugs & $50(100)$ & $100-100$ \\
No & & \\
Alcoholic beverages & $3(6.0)$ & $1.3-16.5$ \\
Yes & $5(1.0)$ & $3.3-21.8$ \\
Not currently & & \\
Physical activities & $18(36.0)$ & $22.9-50.8$ \\
No & $6(12.0)$ & $4.5-24.3$ \\
Not currently & & \\
\hline
\end{tabular}

Regarding lifestyle habits maintained by elderly, the number of active (68.0\%) and passive $(26.0 \%)$. smokers is notable. The amount of sedentary elderly $(48.0 \%)$ is also remarkable. Among these sedentary elderly, 36.0\% reported never having practiced any physical activity.

The tables 3, 4 and 5 below show, respectively, blood pressure classification, from the final mean of blood pressure checked on the first, second and third day of scheduled assessment with the elderly. 
Table 3 - Distribution of elderly according to blood pressure classification on the first day of evaluation. $\mathrm{n}=50$

\begin{tabular}{|c|c|c|}
\hline Systolic pressure & n (\%) & IC $95 \%$ \\
\hline \multicolumn{3}{|l|}{ Systolic arterial pressure 1} \\
\hline Excellent & $10(20.0)$ & $10.0-33.7$ \\
\hline Normal & $6(12.0)$ & $4.5-24.3$ \\
\hline Limitrophe & $13(26.0)$ & $14.6-40.3$ \\
\hline Stage 1 hypertension & $16(32.0)$ & $19.5-46.7$ \\
\hline Stage 2 hypertension & $3(6.0)$ & $1.3-16.5$ \\
\hline Stage 3 hypertension & $2(4.0)$ & $0.5-13.7$ \\
\hline \multicolumn{3}{|l|}{ Diastolic arterial pressure 1} \\
\hline Excellent & $36(72.0)$ & $57.5-83.8$ \\
\hline Normal & $3(6.0)$ & $1.3-16.5$ \\
\hline Limitrophe & $3(6.0)$ & $1.3-16.5$ \\
\hline Stage 1 hypertension & $7(14.0)$ & $5.8-26.7$ \\
\hline Stage 2 hypertension & $1(2.0)$ & $0.1-10.6$ \\
\hline \multicolumn{3}{|l|}{ Final pressure classification 1} \\
\hline Excellent & $9(18.0)$ & $8.6-31.4$ \\
\hline Normal & $6(12.0)$ & $4.5-24.3$ \\
\hline Limitrophe & $13(26.0)$ & $14.6-40.3$ \\
\hline Stage 1 hypertension & $6(12.0)$ & $4.5-24.3$ \\
\hline Stage 2 hypertension & $2(4.0)$ & $0.5-13.7$ \\
\hline Stage 3 hypertension & $1(2.0)$ & $0.1-10.6$ \\
\hline Isolated systolic hypertension & $13(26.0)$ & $14.6-40.3$ \\
\hline
\end{tabular}

The evaluation of blood pressure revealed that $32.0 \%$ of elderly had systolic values within normal limits and $68.0 \%$, altered. Regarding diastolic values, the majority of participants, $78.0 \%$, achieved levels considered adequate. The final classification of blood pressure 1 shows that $70.0 \%$ of elderly had altered blood pressure.

In the first evaluation of blood pressure, participants with blood pressure levels considered inadequate, corresponding to $70.0 \%$, were invited to return in two different days to replicate the procedure.
Table 4 - Distribution of elderly acording to blood pressure classification on the second day of evaluation. $\mathrm{n}=35$

\begin{tabular}{|c|c|c|}
\hline Systolic pressure & n (\%) & IC $95 \%$ \\
\hline \multicolumn{3}{|l|}{ Systolic arterial pressure 2} \\
\hline Excellent & $3(8.6)$ & $1.8-23.1$ \\
\hline Normal & $12(34.3)$ & $19.1-52.2$ \\
\hline Limitrophe & $6(17.1)$ & $6.6-33.6$ \\
\hline Stage 1 hypertension & $13(37.1)$ & $21.5-55.1$ \\
\hline Stage 2 hypertension & $1(2.9)$ & $0.1-14.9$ \\
\hline \multicolumn{3}{|l|}{ Diastolic arterial pressure 2} \\
\hline Excellent & $26(74.3)$ & $37.4-66.3$ \\
\hline Normal & $4(11.4)$ & $2.2-19.2$ \\
\hline Limitrophe & $1(2.9)$ & $0.1-10.6$ \\
\hline Stage 1 hypertension & $4(11.4)$ & $2.2-19.2$ \\
\hline \multicolumn{3}{|l|}{ Arterial pressure 2} \\
\hline Excellent & $3(8.6)$ & $1.8-23.1$ \\
\hline Normal & $11(31.4)$ & $16.9-49.3$ \\
\hline Limitrophe & 5 (14.3) & $4.8-30.3$ \\
\hline Stage 1 hypertension & $5(14.3)$ & $16.9-49.3$ \\
\hline Isolated systolic hypertension & 11(31.4) & $16.9-49.3$ \\
\hline
\end{tabular}

In a second moment, as mentioned, $70.0 \%$ elderly were invited to return to the social assistance reference center for subsequent evaluations. Among these, $60.0 \%$ had still altered pressure values at the second check. Most of the identified alteration was related to systolic blood pressure (57.1\%). Diastolic blood pressures were within normal limits in $85.7 \%$ of the elderly. 
Table 5 - Distribution of elderly according to blood pressure classification in the third valuation date. $n=$ 35

\begin{tabular}{lcc}
\hline Systolic pressure & $\mathbf{n}(\mathbf{\%})$ & IC 95\% \\
\hline Systolic arterial pressure 3 & & \\
Excellent & $4(11.4)$ & $3.2-26.7$ \\
Normal & $5(14.3)$ & $4.8-30.3$ \\
Limitrophe & $7(20.0)$ & $8.4-36.9$ \\
Stage 1 hypertension & $17(48.6)$ & $31.4-66.0$ \\
Stage 2 hypertension & $1(2.9)$ & $0.1-14.9$ \\
Stage 3 hypertension & $1(2.9)$ & $0.1-14.9$ \\
Diastolic arterial pressure 3 & & \\
Excellent & $23(65.7)$ & $47.8-80.9$ \\
Normal & $6(17.1)$ & $6.6-33.6$ \\
Limitrophe & $1(2.9)$ & $0.1-14.9$ \\
Stage 1 hypertension & $5(14.3)$ & $4.8-30.3$ \\
Arterial pressure 3 & & \\
Excellent & $4(11.4)$ & $3.2-26.7$ \\
Normal & $4(11.4)$ & $3.2-26.7$ \\
Limitrophe & $7(20.0)$ & $8.4-36.9$ \\
Stage 1 hypertension & $5(14.3)$ & $4.8-30.3$ \\
Stage 3 hypertension & $1(2.9)$ & $0.1-14.9$ \\
Isolated systolic hypertension & $14(40.0)$ & $23.9-57.9$ \\
\hline
\end{tabular}

In the third evaluation, the same pattern of alterations of previous checks was observed, with predominance of systolic alterations (74.4\%), and among the $74.4 \%$ elderly with inadequate pressure values, $40.0 \%$ were classified as presenting isolated systolic hypertension.

Noteworthy, not all elderly who presented blood pressure values outside the normal range in the first evaluation kept these normal values in subsequent evaluations. Thirty-five elderly were invited for the second day of evaluation of blood pressure. Among these, 21 remained with blood pressure outside normal limits. Even those elderly who had normal blood pressure values on the second evaluation were invited to return for the third time check, when 27 elderly showed yet altered values. Importantly, 16 participants kept altered blood pressure values during the three assessments.

\section{Discussion}

Female participants were predominant in the study (82.0\%). Similar results were found in other studies carried out in several Brazilian regions ${ }^{(2,7)}$. There are similarities in the prevalence of arterial hypertension among men and women, although men are more susceptible to its development up to the fifth decade of life. After this period, there is an inversion in the relationship ${ }^{(5)}$. Also, during the installation of menopause, women have a higher risk of cardiovascular complications ${ }^{(8)}$. It is essential to follow these people in order to detect early alterations and reduce damage from systemic arterial hypertension.

The average age was 70.95 years. There is a correlation between blood pressure and advanced $\operatorname{age}^{(7)}$. The prevalence of arterial hypertension in population aged over 65 years is approximately $58.0 \%{ }^{(6)}$. With respect to the level of education, participant elderly had in average of 4.50 years of study, revealing low schooling level. Low education interferes in the effectiveness of health education strategies, action considered essential to changes in lifestyle. In addition, influences in a negative way the adherence to treatment of diseases ${ }^{(6)}$.

With regard to financial profile, elderly family income was on average $\mathrm{R} \$ 1,357.69$ and individual income, $\mathrm{R} \$ 788.61$. This way, the elder income represents a major source of family income, and he/ she assumes a role of economic support for the family. Financial stability is very important to elderly as enables them to obtain medicines, food and access to health services essential to reach and maintain a healthy life cycle. The financial commitment of elderly with household expenses may interfere to some degree in their quality of life.

Regarding the presence of cardiovascular diseases, hypertension (70.0\%), diabetes mellitus (38.0\%) and altered cholesterol and triglyceride levels (32.0\%) are outstanding. Although diabetes was cited 
less often than hypertension, this is a highly limiting morbidity, with power to cause much damage, as for example, blindness, amputations and kidney, heart and brain complications, and affect the functional capacity of the affected person ${ }^{(9)}$. There is a possible association between hypertension and diabetes in the order of $50.0 \%$. Thus, the clinical management of both chronic diseases is necessary ${ }^{(4)}$, and requires cooperation and commitment by elderly to adhere to proposed treatments as well as more attention from nurses and other health professionals in order to control and reduce the damage caused by these diseases if left uncontrolled.

About dyslipidemias, the literature points to the common occurrence in recent years of increased levels of lipids in the blood such as cholesterol alterations, considered an independent, linear and continuous risk factor for many diseases ${ }^{(10)}$. In the present study, $12.0 \%$ of elderly reported physician-diagnosed heart disease, and $14.0 \%$ reported having experienced at least one episode of stroke. The presence of these non-communicable chronic diseases is related to hypertension, associated with changes in the heart, brain, blood vessels and kidneys, which are identified as target organs. There is also a relation with metabolic changes, a major risk factor for complications such as stroke, acute myocardial infarction and chronic renal disease ${ }^{(7)}$.

To ascertain the presence of chronic diseases, elderly reported never having done exams in order to detect possible alterations or they reported to be unaware of their presence. This fact is evident in the study, as $6.0 \%$ said not to know about the glycemic rates and heart problems and $16 \%$ were unaware of the presence of alterations related to cholesterol or triglycerides. Health actions for prevention and early detection of diseases are fundamental to ensure the quality of life. It is essential to follow the elderly and make them go through regular examinations in order to detect possible alterations and intervene in a timely manner to prevent further compromise of the old person functionality.

With regard to the modifiable risk factors, there are higher percentages of physical inactivity $(48.0 \%)$ and current or past contact with tobacco, either actively (68.0\%) or passively (26.0\%). Smoking causes six million deaths annually, and among these, approximately six hundred thousand are passive smokers. Passive smoking is the third leading cause of death that can be avoided in the world, subsequent to active smoking and alcohol use ${ }^{(11)}$. This information highlights the need for health education activities with the population that makes use of these substances in order to reduce their levels of consumption and to avoid damage to the quality of life.

Cardiovascular diseases are known to be related, among other factors, to sedentary lifestyles. Elderly usually attribute physical inactivity to the advanced age itself ${ }^{(12)}$. Adoption of regular physical activity contributes in several ways to improve the quality of life of seniors by helping them to maintain bone, muscle and joints quality, in order to prevent the development of chronic diseases such as some cancers, cardiomyopathy and diabetes ${ }^{(12-14)}$.

Arterial hypertension is a worldwide public health problem due to its high treatment costs ${ }^{(15)}$, indices in the population and complications consequent of its lack of control ${ }^{(8)}$. Furthermore, it has causal relationship with all of cardiovascular diseases $^{(8)}$. The investigated pressure results show, at the end of the whole procedure, that systolic alterations are more present, in $73.3 \%$ of the sample, compared to diastolic alterations, observed in only $10.0 \%$ of the sample.

The literature describes that the higher the systolic blood pressure, the greater the risk of developing coronary heart disease and emphasizes the condition of isolated systolic hypertension, typical of hypertensive elderly ${ }^{(3)}$. Despite being considered a serious disease that if not treated properly may lead 
to the development of various complications and commitment of organs of major importance, generally the hypertensive person does not consider his illness as serious, and concludes that he/she does not need specialized $\operatorname{care}^{(7)}$. The existence of such perceptions can directly interfere with adherence to treatment and rates of disease control. Therefore, there is a clear need for a direct follow-up to these elderly as well as for developing measures for controlling hypertension and reducing the complications resulting from its installation.

\section{Conclusion}

In this study, reports on the presence of cardiovascular diseases were identified: hypertension (70.0\%), diabetes mellitus (38.0\%) and dyslipidemia (32.0\%). Presence of risk factors for the development of hypertension verified included current or past contact with tobacco, either active $(68.0 \%)$ or passive (26.0\%), and physical inactivity (48.0\%) . Regarding the pressure values, $73.3 \%$ of the sample had blood pressure values outside the normal range.

As a limitation of this research is a mismatch between the operating hours of the social assistance reference center of Redemption and the time available for academics to carry out data collection. Furthermore, there was withdrawal of some participants during the three days of monitoring of blood pressure, which reduced the total number of monitored elderly. Also noteworthy was the superficiality of health guidance provided to elderly with lifestyle habits considered inappropriate.

Based on this study, we suggest the development of educational workshops addressing in more detail the importance of an active lifestyle and also the expansion of the sample to obtain more representative data of the region.

Through this study, it was possible to identify the remarkable presence of altered blood pressure, which is often associated with other chronic diseases. However, the importance of this research is evident when noting that the detection of inappropriate lifestyles among elderly, such as smoking, whether actively or passively, and physical inactivity, may allow for the establishment of practices among health professionals, particularly nurses, targeted to meet the real needs of the elderly.

\section{Collaborations}

Morais PCA, Lima PA, Silva MGF and Ferreira JDF contributed to the design, data collection and analysis, article writing. Moreira RP and Rouberte ESC contributed to data collection, analysis of results, critical review of the relevant intellectual content and final approval of the version to be published.

\section{References}

1. Guedes MB, Rodrigues ST, Ribeiro MJ. Correlação entre hipertensão arterial e capacidade funcional de idosos: uma revisão da literatura. Rev APS. 2013; 16(4):455-9.

2. Silva LSS, Karino ME, Mattos ED, Campos EC, Spagnuolo RS. Perfil epidemiológico dos idosos de uma unidade saúde da família. UNOPAR Cient Ciênc Biol Saúde. 2009; 11(2):27-33.

3. Medeiros TN, Moreira TMM. Avaliação de risco coronariano, adesão terapêutica e qualidade de vida de idosos com hipertensão arterial. Rev Bras Promoç Saúde. 2012; 25(2):76-82.

4. Santos JC, Moreira TMM. Risk factors and complications in patients with hypertension/ diabetes in a regional health district of northeast Brazil. Rev Esc Enferm USP. 2012; 46(5):1125-32.

5. Sociedade Brasileira de Cardiologia. VI Diretrizes Brasileira de Hipertensão Arterial. Rev Bras Hipertens. 2010; 17(1):21-35.

6. Queiroz RF, Alvarez MA, Erdmann AL, França ALM, Pereira CBS. Cardiovascular events and additional risk in hypertensive senior citizens. Rev Rene. 2014; 15(1):52-9. 
7. Lima ER, Barros ARC, Oliveira CAN. Percepção dos clientes hipertensos acerca das complicações da hipertensão arterial sistêmica. Rev Interfaces Saúde Hum Tecnol. 2014; 2(5):1-10.

8. Esperandio EM, Espinosa MM, Martins MAS, Guimarães LV, Lopes MAL, Scala LCN. Prevalência e fatores associados à hipertensão arterial em idosos de municípios da Amazônia Legal, MT. Rev Bras Geriatr Gerontl. 2013; 16(3):481-93.

9. Francisco PMSB, Belon AP, Barros MBA, Carandina L, Alves MCGP, Goldbaum M, et al. Diabetes autoreferido em idosos: prevalência, fatores associados e práticas de controle. Cad Saúde Pública. 2010; 26(1):175-84.

10. Paula CC, Cunha RM, Tufamin AT. Análise do Impacto do treinamento resistido no perfil lipídico de idosos. Rev Bras Ciênc Mov. 2014; 22(1):150-6.

11. Cézar A, Elvis D, Santos JÁ, Barbosa MA, Nascimento RAB, Souza T, et al. Os problemas causados pelos fumantes ativos aos passivos na unit e a criação de um fumódromo. Cad Grad Ciênc Exatas Tecnol. 2014; 2(1):11-20.
12. Ribeiro LB, Rogatto GP, Machado AA, Rogatto PCV. Motivos de adesão e de desistência de idosos a prática de atividade física. Rev Bras Promoc Saúde. 2013; 26(4):581-9.

13. Santos EI, Coco DJSF, Silva JB, Silva TLMM, Santana PPC, Andrade VLFS, et al. Atuação do enfermeiro na promoção da qualidade de vida na terceira idade segundo produções científicas brasileiras. Rev Augustus. 2013; 18(35):51-62.

14. Nogueira IC, Santos ZMSA, Alverne DGBM, Martins ABT, Magalhães CBA. Effects of exercise on hypertension control in older adults: systematic review. Rev Bras Geriatr Gerontol. 2012; 15(3):587-601.

15. Mendes GS, Moraes CF, Gomes L. Prevalência de hipertensão arterial sistêmica em idosos no Brasil entre 2006 e 2010. Rev Bras Med Fam Comunidade. 2014; 9(32):273-8. 